\title{
Methodological features of the rationale for the innovative development of commercial fish farming
}

\author{
Konstantin Tyupakov ${ }^{1}$ and Evgeny Akimov, ${ }^{2 *}$ \\ ${ }^{1}$ Kuban State Agrarian University named after I. T. Trubilin, Krasnodar, 350044, Russia \\ ${ }^{2}$ Russian Federal Research Institute of Fisheries and Oceanography, Moscow, 107140, Russia
}

\begin{abstract}
The article analyzes the category of production efficiency of agricultural products, including technical, technological, social, environmental and economic components, and determines the features of its assessment in relation to the development of commodity fish farming. The contribution of technical, technological, organizational and managerial innovations to the development of domestic commercial fish farming has been substantiated, and a method for its quantitative assessment has been proposed. An author's approach has been developed to determine the level of technical and technological efficiency of commercial fish farming enterprises, implemented by comparing actual and estimated potential production volumes. A methodology for calculating the utilization of the production capacity of a pond farm operating in the specific climatic conditions of the location is proposed. The system of directions for the development of domestic commercial fish farming, which includes the improvement of all stages of production, processing, storage, logistics and sales of products, is justified.
\end{abstract}

\section{Introduction}

Domestic commodity fish farming is an important component in the system of production and processing sectors of the agroeconomy; it plays a significant role in the implementation of the import substitution program and ensuring food security of the country, and partially solves important social problems of rural development. At the same time, market reforms of the agricultural sector of the economy led to the destruction of wellorganized domestic commodity fish farming, which in turn led to a multiple reduction in the volume of production in the sub-sector, a decrease in its competitiveness in the domestic and foreign markets and a high loss ratio of the economic activity of producers. In recent years, domestic commercial fish farming has been showing noticeable positive development results, its pace is still not enough to provide the country's population with high-quality and affordable fish in the amount of recommended consumption standards that meet the requirements of a healthy diet.

In the structure of the main activities of the world fisheries, the role of commodity fish farming is increasing; its total volume amounted to over 85 million tons of fish worth 76.5 billion US dollars in 2018. Over the past 5 years, the share of aqua culture in the total supply of fish and fish products in the world amounted to about $50 \%$, while this figure did not exceed $5 \%$.in Russia. Despite the fact that since the middle of the XX century. the growth rate of fish consumption in the world is 2 times higher than the population of the Earth, the production of salable fish in the country over the past 30 years has decreased by 2.4 times.

Thus, in order to saturate the volumes of domestic production and provide the country's population with domestic products, it is necessary to create new and develop existing enterprises and complexes of commercial fish farming based on the development of advanced achievements of scientific and technological progress. This can be achieved through organizational, technological and managerial innovations, including the cultivation of promising new species and species of fish, the use of safe and effective feeds and additives, methods and forms of organizing production processes that provide resource saving in the sub-industry, etc.

The implementation of these innovative investment processes requires large capital investments, which is currently complicated by the lack of free own funds from agricultural producers and the inaccessibility of borrowed capital.

Comprehensive development of Russia's fisheries is called upon to be ensured by the "Strategy for the Development of the Fisheries of the Russian Federation" [3]. This document envisages increasing the turnover of organizations in the field of fishing, fish farming and fish processing to 888 billion rubles, the volume of catch of aquatic biological resources to 5396 thousand tons, and the production of commercial aquaculture up to 618 thousand tons. In total, it is planned to attract 613 billion rubles of investment for these purposes.

The solution of this problem requires a deep scientific justification of the economic efficiency of the development areas of domestic commercial fish farming.

Corresponding author: akimov@ vniro.ru 
The well-known indicator systems and methods of their calculation in relation to the subject area under study do not fully take into account all the features of the organization and functioning of the sub-industry and require adequate adjustment.

\section{Materials and methods}

The article uses the methods of statistical and mathematical analysis, linear programming to determine the forecast values of the production of commercial fish farming, depending on the cost of production resources. Priorities for the innovative development of domestic commercial fish farming as a whole are determined, taking into account the biological and technological features of the cultivation of certain fish species. In addition, a method is proposed for determining the increase in labor productivity through the introduction of advanced achievements of scientific and technological progress. The priorities of the innovative development of domestic commercial fish farming are identified.

\section{Results and Discussion}

Fishery complex of Russia was created in the middle of the XX century. It is characterized by significant potential for increasing the volumes of catch and production of aquatic biological resources, the volume of which is estimated at 10 million tons. The growth in the consumption of fish and fish products in the country stimulated the development of fish production in inland natural and artificial reservoirs. However, the pace and scale of development of commercial fish farming in Russia lags far behind the level of the world's largest producers (China, Vietnam, Norway, the USA, etc.).In this regard, there is a need to introduce innovations in the activities of the fishery complex and assess the effectiveness of their impact.

The scientific economic literature on the substantiation of the effectiveness of the directions of innovative development of agriculture, its individual sub-sectors and specific enterprises, has already been fairly well developed and described the methods of such an assessment, substantiated priorities and formed a system of recommendations for their practical implementation. Almost all of them note the variety of regional, sectoral, functional, technical, technological and organizational features in the industry and represent a resource approach to their assessment of the effectiveness of innovation [1, 5-7].

Currently, there is still no universally accepted methodology for assessing the economic efficiency of the innovative development of commercial fish farming, adapted to the specific climatic conditions of the place of its placement. When assessing the effectiveness of agroindustrial production, the interconnection is predominantly of the technical, technological, social, environmental and economic components of efficiency $[2,4]$.

With regard to the production of products of the marketable fish farming industry, technological efficiency should be understood as the level of use of the available resource base of specific producers, their groups and clusters, determined by the system of absolute and relative indicators. These indicators should include: the volume of production, current production costs per 1 ha of pond area, feed consumption per unit mass of fish grown, stocking coefficient of pond area, output per 1 ha of used area, production per 1 worker and 1 thousand rubles fixed assets of the fishery.

An important factor in increasing the level of technical and technological efficiency, in our opinion, is the development of technical, technological, organizational and managerial innovations in the production of products, which allows us to reduce the unit costs of all production resources and ensures an increase in output per unit. As a result of the research, an author's approach was proposed to determine the increase in production per one employee, due to the introduction of advanced achievements of scientific and technological progress that can be calculated using formula (1):

$$
Q=\frac{Q_{t}-Q_{t-1}}{n \sqrt{\frac{F_{t}}{F_{t_{1}}}} * r_{t}},
$$

where $Q$ is the annual increase in the production of salable fish per employee of a particular enterprise due to the implementation of the achievements of scientific and technological progress; $Q_{t}, Q_{t-1}$ is marketable fish production per worker, respectively, in the reporting and base year; $F_{t}, F_{t_{1}}$ is capital ratio of one employee of the enterprise, respectively, in the reporting and base year; $n$ is the duration of the analyzed time period; $r_{t}$ is the number of employees in the reporting year.

The solution of equation (1) will determine the annual increase in labor productivity of workers, caused not only by the expansion of the technical base of production through the acquisition of additional equipment and equipment with the same technical and operational characteristics, but by the transition to new production technologies, innovative technical means implementation and progressive forms of labor organization in the enterprise.

An important indicator of assessing the level of technical and process efficiency of commercial fish production is its maximum possible potential volumes that can be achieved in the natural and climatic zones of commercial fish farming with full use of their available area, taking into account the latest achievements of science and technology in the field of fisheries.

The ratio of the calculated values of these potential volumes of production to the actual ones will allow you to get a visual assessment, indicated by the degree of use of its technical and technological base. If its value is equal to one, then this indicates that the commodity producer has reached its potential possibilities of production volumes and its full technical and technological effectiveness. Otherwise, the value of the indicator below unity will indicate the possibility of an increase in production volumes on the basis of the existing areas of water basins and the absence of additional costs of production resources. 
A geometric interpretation of this methodological approach to determining the level of technical and

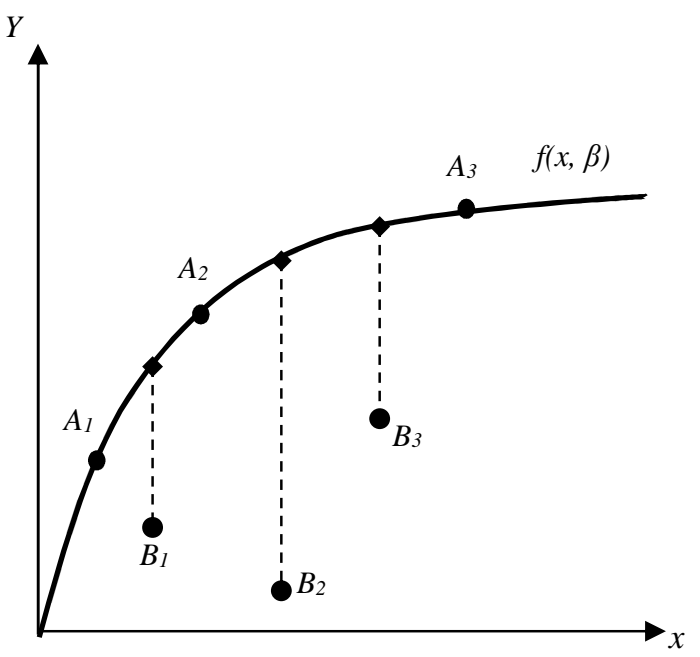

technological efficiency of production of commercial fish products is presented in Figure 1.

a deterministic boundary of possibilities, enveloping a number of producers from above;

$\boldsymbol{A}_{1}, \boldsymbol{A}_{2}, \boldsymbol{A}_{3}$ - producers who ensured the production of products at the level of their potential capabilities;

$\boldsymbol{B}_{1}, \boldsymbol{B}_{2}, \quad \boldsymbol{B}_{3}-$ inefficient commodity producers, in whose activities there are reserves for increasing production volumes to the border

Fig. 1. A geometric interpretation of the methodological approach to determining the level of technical and technological effectiveness of commodity fish farming organizations

In Fig. 1, the curve $f(x, \beta)$ "goes around" all fish farming enterprises from above and shows the maximum possible production volumes for each of them. The quantitatively sought value of these maximum volumes of production can be determined by solving the following linear programming problem for each producer included in a representative selection:

$$
\begin{aligned}
& \sum_{i=1}^{k} y_{i} \lambda_{i} \rightarrow \max , \\
& \left\{\begin{array}{l}
x_{11} \lambda_{1}+x_{12} \lambda_{2}+\ldots+x_{1 k} \lambda_{k} \leq x_{1 t} ; \\
x_{21} \lambda_{1}+x_{22} \lambda_{2}+\ldots+x_{2 k} \lambda_{k} \leq x_{2 t} ; \\
\ldots \ldots \ldots . . \\
x_{n 1} \lambda_{1}+x_{n 2} \lambda_{2}+\ldots+x_{n k} \lambda_{k} \leq x_{n t} \\
\lambda_{1}+\lambda_{2}+\ldots+\lambda_{k}=1 ; \\
\lambda_{1}, \lambda_{2}, \ldots, \lambda_{k} \geq 0,
\end{array}\right.
\end{aligned}
$$

where $y_{i}$ is the volume of fish production by the i-th commodity producer; $x_{j i}$ is the costs of the production resource of the $\mathrm{j}$-th type by the $\mathrm{i}$-th commodity producer; $\lambda=\left(\lambda_{1}, \ldots, \lambda_{k}\right)$ is the vector of non-negative weights; $t$ is the producer index in a representative sample.

The social effectiveness of commercial fish farming can be considered in terms of providing the country's population with the products of the commercial fish farming industry in the required volumes, subject to the conditions of activity necessary to achieve other types of efficiency, as well as the formation of prerequisites for improving the living conditions of the rural population [8].

Ecological production efficiency is a category that characterizes the ability of an enterprise to ensure, during its economic activities, the preservation and reproduction of the natural environment and the production of organic products with rapidly growing market demand.

To assess the economic efficiency of the production of marketable fish, one should use an indicator characterizing the ratio of the value of the gross output or profit of the fishing organization per unit of the fishing area of water bodies.

To achieve high performance indicators for the production of commodity fish, it is important to ensure the fullest possible use of the water bodies in the economy. The coefficient of utilization of the production capacity of the pond economy developed by us has the following form:

$$
K_{t}=\frac{S_{s}}{S_{e} * K_{u}} * \frac{P_{t}}{P_{n}} * \frac{H_{t}}{H_{n}},
$$

where $S_{\mathrm{s}}$ is the stocked feeding area of the pond farm (ha); $S_{e}$ is the total area of reservoirs in the farm (ha); $K_{u}$ is the normative coefficient of use of the pond area, equal to $0.85 ; P_{t}$ is the actual stocking density, units/ha; $P_{n}$ is the standard density of stocking, units/ha; $H_{t}, H_{n}$ are the fish exit coefficients from feeding, corresponding to the actual and regulatory data.

When substantiating the directions of development of pond farms, it is necessary to take into account the possible effect of mixed planting (co-cultivation) of fish by species and age. With this approach, the actual assortment of pond fish products in a particular farm is not always optimal, and therefore, reduces the efficiency of its functioning and requires adjustment.

Moreover, with the narrow specialization of pond fish farming, which involves the cultivation of a single species of fish, the natural fodder resources of the reservoir will not be fully used, which will also reduce the efficiency of the enterprise.

Studies have shown that in many domestic fish farms, the unused area of water bodies is $20-30 \%$, which significantly reduces the volume and efficiency of production of salable fish. Therefore, when determining potential volumes of production, it is important to consider the possibility of including unused area of water bodies in the production process. In this case, it is necessary to carry out the justification and develop a plan for putting these areas into operation in an acceptable time frame. 
With the economic justification of the development directions for commercial fish farming, an important indicator is the system of indicators of the effectiveness of investments in the implementation of planned innovative projects (including the introduction of biotechnologies, the acquisition of innovative technological equipment, diversification of production, etc.). The system of such indicators includes the net discounted income, internal rate of return, profitability index and the discounted payback period of investments.

The studies made it possible to justify the system of priority areas for the development of domestic commodity fish farming (Figure 2).

In the diagram, the priority areas for the innovative development of commercial fish farming are highlighted in accordance with the main stages in the chain of creating the value of fish farming products: reproduction and rearing of commercial fish, organization of its processing with subsequent sale through the system of wholesale and retail enterprises to the final consumer on the market [9].
The successful development of the reproduction and rearing of commercial fish in the domestic fishery complex is associated with the improvement of technologies for growing and maintaining the stock of fish, resulting in resource-saving fish seed stocks and an increase in the environmental safety of production while increasing the fish productivity of commodity fish farming. In addition, improving the organization of feeding based on the use of high-quality feed and feed additives, as well as expanding mutually beneficial integration and cooperation ties will help accelerate production and increase its economic efficiency.

At present, at least three main methods of reproduction and rearing of commercial fish in the domestic fishery complex (traditional pond, pasture and industrial rearing) are known, including the construction and organization of functioning of fish breeding enterprises (factories) of a full production cycle with their own pond farming and the creation of artificial spawning grounds in conditions as close as possible to natural [10].

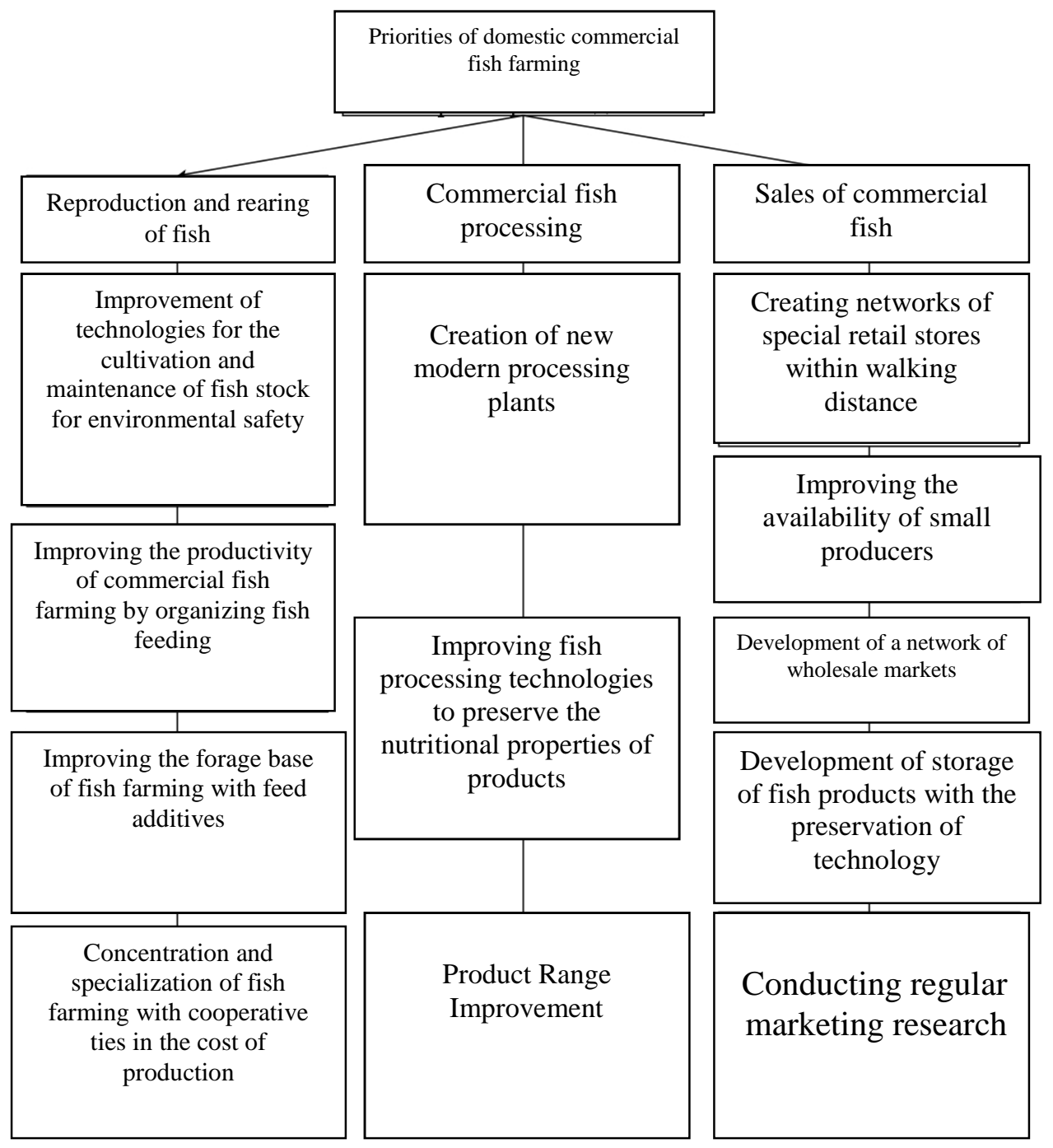

Fig. 2. Scheme of priority areas of innovative development of domestic commercial fish farming

At the same time, it is important, even at the stage of designing commercial fish farming enterprises, to provide such technical and technological solutions that would, to the maximum extent, take into account the specifics of biological features of fish species and breeds planned for breeding. On the other hand, it is important 
to ensure the highly efficient functioning of enterprises, ensuring competitiveness at the price of aquaculture production with fish caught in natural waters.

Currently, the development of commodity fish farming is hampered by the outstripping growth in prices for energy carriers, basic feed and feed additives, fertilizers for forming a natural forage base, planting stock for fish species, etc., which ultimately leads to an increase in the cost of production, which is not offset by an increase in prices for its sale on the market. These negative factors often force producers to switch to extensive methods of fish farming, which significantly reduce the fish productivity of farms.

One of the priority areas for reducing production costs, increasing the efficiency of capital investments in the construction of commercial fish farming enterprises and reducing their payback periods is to improve the species composition of fish, as well as the maximum possible reduction in the length of the production cycle without loss of volume and quality of products. At present, 63 species of fish, crustaceans and mollusks are currently grown in domestic fishery enterprises and complexes, while the main assortment of their products is carp species of fish (58\%), trout and salmon (25\%).

At the stage of processing commercial fish, it is necessary to ensure the creation of new modern and modernization of existing processing shops and enterprises based on the development of world-class technical and technological innovations, improvement of fish processing technologies aimed at the maximum preservation of the taste and nutritional properties of products, improvement of its assortment, packaging and packaging.

At present, the insufficient range of fish products offered on the domestic market is also one of the factors restraining the growth of fish consumption in the country.

At the stage of sale of commercial fish, it is important to ensure the creation of networks of specialized retail stores located within walking distance from potential consumers; increasing the accessibility of small producers to product sales markets, including large retail chains; development of a network of wholesale markets, storage of fish products with improved technologies and refrigeration equipment; conducting regular marketing research of markets in various price segments and using the results obtained in the development of the sub-industry, etc.

\section{Conclusion}

The studies conducted allowed us to draw the following main conclusions.

1. Domestic commodity fish farming has a huge resource potential for development, represented by vast areas of inland water bodies and marine areas suitable and accessible for aquaculture, which are currently used only by $1 \%$.

The analysis showed that organizing the effective use of available resources will allow us to achieve multifold increase in the volume of domestic production of fish and fish products and thereby completely solve the problem of import substitution of this important type of food. This can only be achieved with the implementation of high-quality transformations of domestic commodity fish farming through development in the production of technical, technological and organizational and managerial innovations.

2. Specific methods have been proposed for the economic justification of the directions of innovative development of commodity fish farming, namely, methods for determining the level of technical and technological efficiency of a commodity fish producer, based on a comparison of actual production volumes with possible achieved volumes. Which are determined according to the data of advanced enterprises operating in similar climatic conditions and using the same production technologies with similar dimensional characteristics of water resources. A technique is given for calculating the utilization of available pond areas, taking into account their total and stocked areas, stocking density and fish exit from the feeding ground. Estimates of the contribution to the growth of fish production as a result of the development of technical, technological and organizational and managerial innovations are given.

3. The development of domestic commercial fish farming is currently constrained by weak legal regulation of the sub-sector, large depreciation of fixed assets of enterprises and complexes, poor development of breeding and breeding work and a shortage of highquality domestic fish seed stocks, import dependence of commodity producers in machinery and technological equipment, low investment attractiveness and low level of state support. Solving these problems requires a systematic approach, focused on improving all stages of production, processing and marketing of commercial fish products.

4. As a result of the studies, a system of priority areas for the development of domestic commercial fish farming was substantiated, including improvement of the species composition of aquaculture, technologies for growing, keeping and feeding fish, forms and methods of organizing production processes; cooperation and integration of enterprises; development of the sphere of processing, storage, logistics and sales of finished products to the end consumer in the market.

\section{References}

1. A.I. Altuhov, V.I. Nechaev, Economic problems of the innovative development of the grain product complex of Russia (Moscow, 2015)

2. I.S. Sandu, V.I. Nechaev, Increasing innovation activity as a priority for the scientific and technical development of the agro-industrial complex, in: Development of Innovation Economy Institutions in the Context of Russia's Integration into the World Economic Space: Proceedings of the International Scientific and Practical Conference, pp. 11-14 (2016) 
3. The development strategy of the fishery complex of the Russian Federation for the period until 2030, Order of the RF government dated 26.11.2019, no. 2798-r. Retrieved from: https://www.garant.ru/ products/ipo/prime/doc/72972854/

4. A.I. Trubilin, Substantiation of directions and evaluation of the effectiveness of innovative development of import-substituting industries of the Krasnodar Territory (Krasnodar, 2019)

5. A.I. Trubilin, Yu.I. Bershickij, K.E. Tyupakovi et al., Theory, methodology and results of substantiation of the directions of innovative development of agroeconomics of the Krasnodar Territory (Krasnodar, 2018)

6. A.I. Trubilin, The essence of innovation potential in agriculture, AIC, Econ., Management 10, 21 (2010)

7. I.G. Ushachev, I.S. Sandu, G.M. Demishkevich et al., Formation of the innovation system of the agro- industrial complex: mechanism of public-private partnership (Moscow, 2014)

8. A.I. Altukhov, A.V. Bogoviz, I.M. Kuznetsov, Creation of an information system - a necessary condition of rational organization of agricultural production, Advan. in Intellig. Syst. and Comput. 726, 800-809 (2019)

9. V.I. Nechaev, A.V. Bogoviz, N.R. Saifetdinova, Theoretical aspects of state regulation of agriculture within the classical and phsiocratic schools: a modern view, Advan. in Intellig. Syst. and Comput. 726, 870-884 (2019)

10. Yu.I. Bershitsiy, N.R. Saifetdinova, K.E. Tyupakov et al., Justification of the structure and size of major productive resources of agricultural organizations, Int. J. of Appl. Busin. and Econ. Res. 14(10), 72677287 (2016) 